\title{
Impact of COVID-19 Lockdown on Admissions to a Tertiary Maternity Hospital in Srinagar
}

\author{
Ambreen Qureshi ${ }^{1}$, Ufaque Muzaffar ${ }^{2}$
}

\begin{abstract}
Introduction: The first case of new pneumonia of unknown origin was found in Wuhan (China) on December 31, 2019. The causative virus was identified from throat swab samples in the Chinese Centre for Disease Control and Prevention (CCDC) on January 7, 2020, and it was named severe acute respiratory syndrome coronavirus (SARS-CoV-2). Subsequently, World Health Organization (WHO) renamed it COVID-19. COVID-19 was a highly infectious newly discovered coronavirus, which led to a worldwide pandemic. It has shown an equal number of cases between men and women, but a lower mortality rate in women.

Materials and methods: A retrospective observational study was conducted in the Department of Obstetrics and Gynaecology of GMC, Srinagar, comparing the total number of emergency admissions including obstetric emergencies, such as ectopic pregnancy, intrauterine device (IUD), severe anemia, eclampsia, abruption, obstructed labor, and postpartum hemorrhage (PPH) during a period of 6 months from March 2020 to August 2020 with that from March 2019 to August 2019.

Results: A total of 13,784 patients were admitted over a period of 6 months from March 2020 to August 2020, and there was a significant decline in the admissions as compared to pre-COVID-19 period of March 2019 to August 2019 ( $p$-value, 0.007).

Conclusion: The COVID-19 lockdown greatly reduced the rate of admission to gynecological and obstetric emergencies. This reduction allowed for more effective and efficient use of emergency services and will inspire policymakers to implement policies for efficient utilization of emergency services in the future.

Keywords: Abruption, Anemia, Eclampsia, Intrauterine death.

Journal of South Asian Federation of Obstetrics and Gynaecology (2021): 10.5005/jp-journals-10006-1857
\end{abstract}

\section{INTRODUCTION}

The first case of new pneumonia of unknown origin was found in Wuhan (China) on December 31, 2019.' The causative virus was identified from throat swab samples in the Chinese Centre for Disease Control and Prevention (CCDC) on January 7, 2020, and it was named severe acute respiratory syndrome coronavirus (SARS-CoV-2). Subsequently, World Health Organization (WHO) renamed it COVID-19. ${ }^{2}$ COVID-19 was a highly infectious newly discovered coronavirus, which led to a worldwide pandemic. It has shown equal number of cases between men and women, but a lower mortality rate in women. ${ }^{3,4}$ The new beta coronavirus, the SARS-CoV-2, known as COVID-19 was highly infectious, particularly during the asymptomatic period of incubation, with a low rate of consequent mortality. Therefore, it kept spreading, became pandemic, and resulted in a worldwide health crisis of rapid evolution with consequent socioeconomic effect due to international strict measurements of lockdowns and border closures. ${ }^{5-7}$ On January 30, 2020, the WHO proclaimed that it was a public health emergency of international concern. Already on January 23, 2020, a strict lockdown had been enforced in Wuhan and other cities of Huber province of China as an unprecedented measure to control the spread of the virus. Though this move was met with skepticism even by the $\mathrm{WHO}$, as the virus spread and pandemic worsened, similar measures were taken all around the world. In India, on March 24, 2020, a 21 days lockdown was announced by the Prime Minister after a 14 hours voluntary Janta Curfew. This was to control the spread of the virus when the number of cases was at 500 in India. This lockdown was then extended three times till May 31, 2020, after which the unlock strategy was announced. The lockdown in India, which has been
1,2Department of Obstetrics and Gynaecology, GMC Srinagar, Srinagar, Jammu and Kashmir, India

Corresponding Author: Ufaque Muzaffar, Department of Obstetrics and Gynaecology, GMC Srinagar, Srinagar, Jammu and Kashmir, India, Phone: +91 9419984533, e-mail: ufaque3@gmail.com

How to cite this article: Qureshi A, Muzaffar U. Impact of COVID-19 Lockdown on Admissions to a Tertiary Maternity Hospital in Srinagar. J South Asian Feder Obst Gynae 2021;13(1):55-57.

Source of support: Nil

Conflict of interest: None

called the biggest and strictest in the world, saw many people pushed out of work, many migrant workers walking barefooted in the hottest months in the subcontinent, and many deaths while these people were walking back home. Pregnant women are affected by this virus. The impact of COVID-19 on this category of patients and their fetuses at the different stages of pregnancy is subjected to multiple discussions. Questions are also raised concerning the long-term effects on the patients and the vertical transmission to newborns. Its impact on pregnancy cannot be negligible, especially if the maternal and fetal complications due to other types of coronaviruses in previous epidemics are taken into consideration. ${ }^{8}$ It is evident that the sociodemographic characteristics and presumed predisposing risk factors are of high importance. The subject of COVID-19 in pregnancy is a matter of concern. At first, the pregnancy itself is a state of vulnerability due to the correlated physiological and mechanical changes not only at the level of the cardiopulmonary and immune system but also the associated hypercoagulable 
state. We hereby report the experience of the department of obstetrics and gynaecology at a tertiary maternity unit in LD Hospital, GMC Srinagar.

\section{Aims and Objectives}

The aim of the present study was to evaluate the extent by which the lockdown, imposed by the government, has impacted the activity of admissions to the tertiary maternity hospital in Srinagar.

\section{Materials and Methods}

A retrospective observational study was conducted in the Department of Obstetrics and Gynecology of GMC Srinagar, comparing the total number of emergency admissions including obstetric emergencies, such as ectopic pregnancy, intrauterine device (IUD), severe anemia, eclampsia, abruption, obstructed labor, and postpartum hemorrhage (PPH) during a period of 6 months from March 2020 to August 2020 with that from March 2019 to August 2019.

\section{Results}

- As mentioned in table (Table 1) the total of 13,784 patients were admitted over a period of 6 months from March 2020 to August 2020, and there was a significant decline in the admissions as compared to pre-COVID-19 period of March 2019 to August 2019 ( $p$-value, 0.007).

- There was a significant increase in the number of patients admitted with IUD from March 2020 to August 2020 as compared pre-COVID-19 data of March 2019 to August 2019 ( $p$-value, $0.00008)$

- There was a significant increase in the number of patients with eclampsia from March 2020 to August 2020 as compared to pre-COVID-19 data of March 2019 to August 2019 ( $p$-value, 0.04)

- There was a significant increase in the number of patients with severe anemia admitted from March 2020 to August 2020 as compared to pre-COVID-19 data of March 2019 to August 2019 ( $p$-value, 0.03)

- There was no significant difference observed in patients admitted with ectopic, abruption ( $p$-value, 0.30$)$, obstructed labor ( $p$-value, 0.80$)$, and PPH ( $p$-value, 0.80$)$

\section{Discussion}

Emergencies were increasingly being utilized for nonemergent obstetric care during non-COVID-19 times. ${ }^{9}$ Up to one-third of patients seen in the emergencies have problems that could have potentially been addressed in an outpatient setting..$^{10}$ Use of the emergencies for nonurgent conditions may lead to excessive health care spending, unnecessary testing and treatment, and weaker relationships between patients and primary health-care providers. ${ }^{11}$

The results of the present study suggest that during the COVID-19 lockdown, real emergencies have been filtered from more deferrable cases, increasing the number of hospitalized women, especially for emergent surgeries. Furthermore, the COVID-19 epidemic could have challenged the capability of health-care systems to deal with emergencies. ${ }^{12}$ Many governments and directors of hospitals and other medical institutions decided to restrict the number of outpatient medical consultations, as well as routine elective surgeries, because they face challenges
Table 1: Comparison of admissions of gynecological and obstetric emergencies

\begin{tabular}{|c|c|c|c|}
\hline & $\begin{array}{l}\text { March } 2020 \text { to } \\
\text { August } 2020 \\
\text { (COVID-19 data) }\end{array}$ & $\begin{array}{l}\text { March } 2019 \text { to } \\
\text { August } 2019 \\
\text { (pre-COVID-19) }\end{array}$ & $p$-value \\
\hline Total admission & 13,784 & 17,937 & 0.007 \\
\hline Intrauterine death & 486 & 212 & 0.00008 \\
\hline $\begin{array}{l}\text { Ectopic pregnancy- } \\
\text { ruptured }\end{array}$ & 128 & 108 & 0.90 \\
\hline $\begin{array}{l}\text { Ectopic pregnancy- } \\
\text { unruptured }\end{array}$ & 112 & 109 & 0.80 \\
\hline Severe anemia & 342 & 159 & 0.03 \\
\hline Eclampsia & 50 & 27 & 0.40 \\
\hline Abruption & 22 & 27 & 0.30 \\
\hline Obstructed labor & 20 & 29 & 0.80 \\
\hline PPH & 20 & 24 & 0.80 \\
\hline
\end{tabular}

providing health care to patients with COVID-19 and also argue that these restrictions are to reduce the risk of contamination to both health-care providers and patients. No restrictions were possible on the opportunity to seek medical attention in the emergencies for urgent health problems. As in the present study, the total number of admissions was significantly reduced as was observed by Oseran et al. ${ }^{13}$ In our study, it was observed that there was a significant increase in patients with eclampsia as observed by Rodruguez et al. ${ }^{14}$

\section{Conclusion}

The COVID-19 lockdown greatly reduced the rate of admission to gynecological and obstetric emergencies. This reduction allowed for more effective and efficient use of emergency services and will inspire policymakers to implement policies for efficient utilization of emergency services in the future.

\section{References}

1. Lu H, Stratton CW, Tang Y. Outbreak of pneumonia of unknown etiology in Wuhan China: the mistery and the miracle. J Med Virol 2020;92:401-402. DOI: 10.1002/jmv.25678.

2. World Health Organization. WHO director-general's remarks at the media briefing on 2019-nCoV on 11 February 2020.

3. Grandi G, Facchinetti F, Bitzer J. The gendered impact of coronavirus disease (COVID-19): do estrogens play a role? Eur J Contracept Reprod Health Care 2020;25:233-234. DOI: 10.1080/13625187.2020.1766017.

4. Cagnacci A, Xholli A. Age-related difference in the rate of COVID-19 mortality in women versus men. Am J Obstet Gynecol 2020;223: 453-454. DOI: 10.1016/j.ajog.2020.05.039.

5. Li X, Geng M, Peng Y, et al. Molecular immune pathogenesis and diagnosis of COVID-19. J Pharm Anal 2020;10:102-108. DOI: 10.1016/ j.jpha.2020.03.001.

6. Wang W, Xu Y, Gao R, et al. Detection of SARS-COV-2 in different types of clinical specimens. JAMA 2020;323:1843-1844. DOI: 10.1001/ jama.2020.3786.

7. Rasmusen S, Smulian J, Lednicky J, et al. Coronavirus disease 2019 and pregnancy: what obstetricians need to know. AJOG 2020;222: 415-426. DOI: 10.1016/j.ajog.2020.02.017.

8. Masmejan S, Pomar L, Lepigeon K, Favre G, Baud D, Rieder W. COVID-19 et grossesse [COVID-19 and pregnancy]. Rev Med Suisse. 2020 May 6;16(692):944-946. French. PMID: 32374542. 
9. Kilfoyle KA, Vrees R, Raker CA, et al. Nonurgent and urgent emergency department use during pregnancy: an observational study. Am J Obstet Gynecol 2017;216:181.e1-181.e7. DOI: 10.1016/ j.ajog.2016.10.013.

10. Uscher-Pines L, Pines J, Kellermann A, Gillen E, Mehrotra A. Emergency department visits for nonurgent conditions: systematic literature review. Am J Manag Care. 2013 Jan;19(1):47-59. PMID: 23379744; PMCID: PMC4156292.

11. Matteson KA, Weitzen SH, Lafontaine D, et al. Accessing care: use of a specialized women's emergency care facility for nonemergent problems. J Womens Health 2008;17:269-277. DOI: 10.1089/ jwh.2006.0292.
12. De Rosa S, Spaccarotella C, Basso C, et al. Reduction of hospitalizations for myocardial infarction in Italy in the COVID-19 era. Eur Heart J 2020;41:2083-2088. DOI: 10.1093/Eurheartj/Ehaa409.

13. Oseran AS, Nash D, Kim C, et al. Changes in hospital admissions for urgent conditions during COVID-19 pandemic. Am J Manag Care 2020;26(8):327-328. DOI: 10.37765/ajmc.2020.43837.

14. Garcia Rodriguez A, Marcos Contreras S, Fernandez Manovel SM, et al. SARS-COV-2 infection during pregnancy, a risk factor for eclampsia or neurological manifestations of COVID-19? Case report. BMC Pregnancy Childbirth 2020;20:587. DOI: 10.1186/ s12884-020-03275-2. 